\title{
Risks of elective cardiac surgery: what do patients want to know?
}

\author{
N Beresford, L Seymour, C Vincent, N Moat
}

\begin{abstract}
Objective-To examine patients' individual requirements for risk disclosure before surgery. Design-Structured interview and questionnaire.

Setting-50 patients interviewed following coronary artery bypass grafting or valve replacement or repair.

Main outcome measures-Patient assessment of the nature and probability of risks they would have wished to be informed of from a pool comprising death and 13 postoperative complications. Results-Out of 50 patients, $21(42 \%)$ wanted no risk information at all, $25(50 \%)$ did not want to be advised of the risk of death, and 27 (54\%) did not want information about the risk of permanent stroke. This contrasts with standard practice of routinely informing patients of the risk of death and stroke. However, there were pronounced individual patient preferences. Three groups of patients emerged: those requiring little or no risk information, those requiring information about major risks, and those requiring full risk disclosure. Patients were not generally concerned about the specific probabilities of any risk.

Conclusions-Clinicians counselling patients before operation should routinely discuss patient preferences before risk disclosure, distinguishing among a preference for "no risk information", "all potentially relevant risks", and "those risks considered significant or likely to occur". The fact of individual patient preferences may undermine the concept of the "reasonable patient" in determination of the legal requirements for risk disclosure. Future studies, in addition to replicating the present findings, should examine the reasons underlying individual patient preferences and the long term implications of degrees of risk disclosure, particularly when adverse outcomes occur.
\end{abstract}

(Heart 2001;86:626-631)

Keywords: cardiac surgery; risk; patient information

Clinicians face three challenges when attempting to convey risk information to patients: those of assessing and explaining risks, conveying risk probabilities, and deciding which risks to disclose. ${ }^{12}$ This study was concerned principally with the third challenge, that of deciding which risks to disclose. The area of risk disclosure is under researched and highlights a pressing clinical problem in that either under or over disclosure of risk may adversely affect treatment choice, damage the clinician-patient relationship, and provide fertile ground for dissatisfaction, complaint, or claim. On the other hand, conveying accurate risk information appropriate to the individual patient may improve clinical outcome and reduce inpatient length of stay. ${ }^{3}$

Harefield NHS Trust, Sydney Street, London SW3 6NP, UK

$\mathrm{N}$ Beresford

N Moat

University College

London, Clinical Risk

Unit, Psychology

Department, 1-19

Torrington Place, London WC1E 6BT, UK

L Seymour

C Vincent

Correspondence to:

Dr Beresford

n.beresford@

rbh.nthames.nhs.uk

Accepted 4 June 2001 Assessing risk factors for populations is itself problematic. For instance, risk factors for coronary artery bypass grafting (CABG) are different for populations in the USA and in the $\mathrm{UK}$; therefore, risk algorithms developed for patients in the USA are of limited use in predicting mortality in the UK. ${ }^{4}$ Assessing risks for individual patients involves further uncertainty. Individual risk varies with the severity of the condition, mode of treatment, and comorbidity. Having assessed and explained the risks of a procedure, clinicians have no guarantee that patients will retain or correctly understand risk information. ${ }^{5}$ There is also evidence that priorities of patients and clinicians may not coincide in all circumstances. For example, patients with malignant disease may give greater weight to short term side effects of treatment than do their treating clinicians. ${ }^{6}$

A further difficulty is that of conveying risk information in an appropriate form. Clinicians may be accustomed to communicating risk in numerical form; patients, however, may fail to understand numerical estimates with sufficient accuracy to ensure appropriately informed consent. For example, people are known to have difficulty with numerical representations of risk where they are required to convert percentages (for example, 10\%) to proportions (1 in 10). ${ }^{78}$ Other problems may arise when risk information is presented by category, with named categories, such as "low risk", being subject to widely differing interpretation by different people in different contexts. ${ }^{9}$

This study examined the difficulty of decid- ing which risks to disclose. Patients may differ greatly in the amount of information they require to make a decision. A clinician's attempt to give a detailed presentation of risks and benefits may conflict with a patient's wish to remain ignorant of risks and to delegate decision making to their treating clinician. Given the complexity of some of the clinical issues involved, this may be understandable but is liable to encourage outmoded and paternalistic approaches to risk disclosure. Clinicians may then have to decide whether to "force" risk 
information on patients who prefer not to receive it.

MEDICOLEGAL CONSIDERATIONS

Although it is a natural part of good practice, adequately informed consent is also a necessary defence. Clinicians are vulnerable to allegations relating to consent and risk disclosure when significant complications arise, especially those involving permanent or severe injury. In such cases, inadequate risk disclosure may lead to a successful claim, even in the absence of negligent treatment. However, legal guidance on the degree of disclosure required to meet the standard of informed consent remains unclear. Although the doctrine of informed consent has yet to be widely acknowledged in case law, in the UK at least, the guidelines put forward in the precedent case of Sidaway $v$ Bethlem \& Maudsley Hospitals remain the yardstick. ${ }^{10}$ In essence, following Sidaway $v$ Bethlem \& Maudsley Hospitals, it is deemed acceptable practice not to disclose a risk occurring with a frequency of less than 1 in 100 cases. However, clinical experience suggests that some patients wish to be informed of "significant" risks, no matter how rarely they occur.

Clinicians may wish also to consider the recent Court of Appeal decision, Pearce $v$ United Bristol Healthcare NHS Trust, which arguably heralds the courts' acceptance of the doctrine of "informed consent" and contains specific advice on how to approach risk disclosure:

if there is a significant risk which would affect the judgement of a reasonable patient, then ... it is the responsibility of a doctor to inform the patient of that risk if the information is needed so that the patient can determine ... what course he or she should adopt [emphasis added].

It therefore becomes a matter of some importance to discover how much information patients need to decide "what course they should adopt" or, in other words, to discover "what do they want to know?"

RESEARCH ON INDIVIDUAL PATIENT NEEDS FOR RISK INFORMATION

The few studies that have addressed the question of which risks should be disclosed have yielded conflicting results. In a study of information preferences in a trial of chemotherapy, most patients expressed a desire for more detailed information and a more comprehensive consent form. ${ }^{12}$ In contrast, a study of patients undergoing elective cardiac surgery found that $48 \%$ did not wish to receive additional written material detailing risks and benefits. ${ }^{13}$ A further study investigating the informational needs of patients with malignant prostatic disease showed sufficient agreement among patients to define a core set of topics to be addressed from a pool of 95 items. However, each of the remaining items was judged essential to at least one patient. ${ }^{14}$ Both research and clinical experience therefore indicate a wide range of patient preference, perhaps influenced by the context of consultations, the nature of proposed treatments, the consequence of risks eventuating, and the balance of risks and benefits.

In summary, there is conflicting evidence about the information requirements of patients in general and cardiac surgery patients in particular. The present paper reports results from the first of two studies and has three objectives. It aims, firstly, to identify the risks that patients generally wish to be informed about, secondly, to identify groups of patients with different information requirements, and thirdly, to identify individual patients' risk information "thresholds" - that is, how much and what type of risk information do they need? A second study, to be reported separately, examines current views and practice of British cardiac surgeons regarding the provision of risk information.

\section{Methods}

PATIENTS

All subjects were postoperative patients attending Royal Brompton Hospital (RBH) between 24 February 2000 and 24 May 2000 for follow up, having undergone either CABG or valve replacement or repair. Patients with a psychiatric history or with a limited command of English were excluded. Fifty seven patients were approached to participate in the study. Fifty one patients consented to participate, with one patient being excluded because the interview was not completed. Fifty patients completed interviews, of whom $74 \%$ were men. Their ages ranged from 30-83 years with a mean age of 62.74 years. Of these patients, $56 \%$ had no formal educational qualifications; $14 \%$ were educated to degree level. Twenty four patients $(48 \%)$ had undergone CABG, $21(42 \%)$ had undergone valve replacement or repair, and five patients $(10 \%)$ had undergone both CABG and valve replacement or repair.

DEVELOPMENT OF STRUCTURED INTERVIEW A structured interview process and accompanying coding sheet were devised for the study. An initial review of the surgical literature on the outcome of CABG and valve surgery identified eight potential complications. These were associated with a risk of $0.1 \%$ or greater, based on figures published by $\mathrm{RBH}$. UK morbidity figures were used where data from $\mathrm{RBH}$ were not available.

The interview addressed five principal areas:

- patient experience of complications;

- complications about which patients were informed before consenting to surgery;

- complications about which patients wished to be informed;

- quantity and type of risk information required by patients;

- influence of risk information on decisions to accept or decline treatment.

The schedule was redrafted in response to comments and suggestions by three cardiac surgeons, paying particular attention to the specification of potential complications. It was then pilot tested with 15 patients, who found the interview questions clear and unambiguous. Minor revisions were made to adapt it for 
use in the main study. After further consultation with cardiac surgeons, the number of complications included in the study interview was increased to 14 .

INFORMATION CURRENTLY PROVIDED TO PATIENTS UNDERGOING CARDIAC SURGERY Surgeons at $\mathrm{RBH}$ routinely discuss risks of death and neurological damage but few other risks. This was confirmed in an initial pilot study of 30 patients. ${ }^{15}$ Two cardiac surgeons followed their usual practice of giving explicit verbal estimates of operative risk to individual patients. With the patients' consent, consultations were audiotaped for later analysis.

Analysis of the tapes indicated that all patients were informed about risk of death and just over half (53\%) were informed about the risk of neurological damage. Additional risks consequent on arterial disease (two patients) and diabetes (one patient) were also discussed but no other information on morbidity related to the procedures was given or requested.

In addition to the consultation, at which patients receive individualised information, potential candidates for elective cardiac surgery at RBH are offered an extensive preoperative educational programme. This is designed to assist their understanding of the surgical procedures and of potential consequences. Individual risk information may be reiterated when consent is obtained by medical staff at the preadmission clinic. The initial outpatient consultation is the first phase of this programme. The full programme is shown in the appendix.

Table 1 Percentage of patients reporting complications by operation type

\begin{tabular}{lcclc}
\hline Complication & $\begin{array}{l}\text { All } \\
(n=50)\end{array}$ & $\begin{array}{l}\text { CABG } \\
(n=24)\end{array}$ & $\begin{array}{l}\text { Valve } \\
(n=21)\end{array}$ & $\begin{array}{l}\text { CABG +Valve } \\
(n=3)\end{array}$ \\
\hline Permanent stroke & 0 & 0 & 0 & 0 \\
Permanent cognitive disability & 0 & 0 & 0 & 0 \\
Reoperation & 4 & 0 & 9.5 & 0 \\
Myocardial infarction & 2 & 4.2 & 0 & 0 \\
Arrhythmia & 12 & 12.5 & 9.5 & 20 \\
Kidney failure & 2 & 4.2 & 0 & 0 \\
Pulmonary embolus & 0 & 0 & 0 & 0 \\
Deep vein thrombosis & 0 & 0 & 0 & 0 \\
Pleural effusion & 30 & 25 & 33.3 & 40 \\
Wound problems & 22 & 25 & 19.2 & 20 \\
Failure of sternal union & 2 & 0 & 0 & 20 \\
Transient stroke & 4 & 4.2 & 0 & 20 \\
Transient cognitive disability & 4 & 0 & 9.5 & 0 \\
\hline
\end{tabular}

CABG, coronary artery bypass grafting

Table 2 Information provided to and desired by patients

\begin{tabular}{lll}
\hline Complication & $\begin{array}{l}\text { Patients who reported being informed } \\
\text { of risk of complication (\%) }\end{array}$ & $\begin{array}{l}\text { Patients who wanted } \\
\text { information (\%) }\end{array}$ \\
\hline Death & 72 & 46 \\
Permanent stroke & 40 & 38 \\
Permanent cognitive disability & 20 & 40 \\
Reoperation & 14 & 34 \\
Myocardial infarction & 34 & 34 \\
Arrhythmia & 20 & 34 \\
Kidney failure & 22 & 36 \\
Pulmonary embolus & 16 & 30 \\
Deep vein thrombosis & 14 & 36 \\
Moderate pleural effusion & 14 & 36 \\
Wound infection & 22 & 28 \\
Failure of sternal union & 10 & 34 \\
Transient stroke & 14 & 32 \\
Transient cognitive disability & 16 & 36 \\
\hline
\end{tabular}

PROCEDURE

Patients were recruited to the study at routine outpatient follow up. Of the patients, $48 \%$ attended between 6 and 12 weeks postoperatively, $18 \%$ between three months and one year, $24 \%$ between one and three years, and $12 \%$ three or more years after surgery.

Patients were asked to participate in a study to investigate what information future patients might wish to receive before accepting surgical treatment. They were given an information sheet about the study and were invited to ask any further questions before deciding to participate. They were assured of confidentiality, that the research would have no bearing on their own treatment, and that their consultant was likely to have discussed any postoperative complications applicable to their own case. Those included in the study gave written consent to participation and were then interviewed by the researcher. The Royal Brompton and Harefield NHS Trust/National Heart and Lung Institute Ethics Committee approved this study.

\section{Results}

COMPLICATIONS REPORTED BY PATIENTS

Table 1 shows the percentage of patients reporting complications by operation type. The most common reported complications were moderate pleural effusion and wound infection.

Overall $40 \%$ reported no complications, $40 \%$ a single complication, $16 \%$ two complications, and $4 \%$ three complications. Patients' experience and recall of complications were considered the most important variable in this study with respect to the effect of postoperative complications on desire for risk information (see below). Patients' reports of complications were nevertheless checked against available hospital information and found to be consistent with clinical records. Patients did however describe a wider range of events as complications, thus raising the apparent complication rate. For instance, few of the wound problems reported by patients would have been described as a serious wound infection in surgical terms.

INFORMATION PROVIDED TO AND DESIRED BY PATIENTS

Table 2 shows risk information that patients reported being given before surgery, contrasted with risk information they would ideally have liked to receive. Seventy two per cent of patients reported being informed of the risk of death and $40 \%$ of the risk of neurological damage. Earlier findings from a pilot study indicated that patients are counselled about the risk of death in almost all cases and the risk of stroke in $40 \%$ of cases, suggesting that some patients failed to recall some of the information imparted during the initial consultation.

Less than $50 \%$ of patients wished to be informed of even the most serious risks- that is, death and neurological damage. In practice, almost all patients are informed of these risks. In contrast, comparatively few patients are informed about more remote or less significant 
Table 3 Patients'views on the provision of risk information

\begin{tabular}{|c|c|}
\hline Patients who want little or no information & $\begin{array}{l}\text { "Ignorance (about operative risks) is bliss." "People with no medical knowledge are } \\
\text { not interested in complications." "If risks are known then trust in the surgeon would } \\
\text { be diminished." }\end{array}$ \\
\hline Patients who want some information & $\begin{array}{l}\text { "I would want to know that there is a risk but breaking it down at that stage (initial } \\
\text { outpatient consultation) is not helpful." "It is sensible to be told a clear } 98 \% \text { success } \\
\text { rate. There should be a single all embracing statement saying "things could go } \\
\text { wrong." "Patients should be told that there is a percentage risk that the operation is } \\
\text { not a success. That is sufficient." }\end{array}$ \\
\hline Patients who want full information & $\begin{array}{l}\text { "I would want to know about risks-though I might not ask. I would like to know } \\
\text { what the surgeon's success rate is in a particular operation. The more questions } \\
\text { asked by the patient the better." "I took trouble to find out about the risks and wrote } \\
\text { to the British Heart Foundation. Knowing the risks made it easier." "If you know } \\
\text { about (a particular complication) before the operation it would help you to prepare." }\end{array}$ \\
\hline
\end{tabular}

risks, though rather more patients want information about these than currently receive it. Neither sex, age, nor operation type predicted patient desire for risk information. There were no significant associations between the level of information desired and the incidence of postoperative complications, either reported by patients or recorded by clinicians.

\section{INDIVIDUAL PATIENT REQUIREMENTS FOR RISK}

INFORMATION

Patients wanted information about, on average, five complications. However, these figures mask considerable individual variation: $42 \%$ of patients stated that they did not want any information about risks; $18 \%$ wished to be provided with information about one or two risks (death and stroke); $26 \%$ wished to be advised about 10 or more risks: and the remaining $24 \%$ wanted information on between three and nine risks.

This spectrum of information requirements can most simply be represented by considering three groups of patients: those requiring little or no information, those requiring information about major risks, and those requiring full or near full disclosure of all risks. Some illustrative comments are shown in table 3.

LEVEL AT WHICH PATIENTS WISH TO BE INFORMED OF RISKS

Patients who wished to be informed of complications were asked at what level of probability they would want to be informed. The probability of adverse outcome appeared not to be an important factor. Patients appeared either to want no risk information at all or to want information irrespective of the probability of occurrence. Few patients differentiated between varying levels of risk (table 4).

Table 4 Level at which patients wish to be informed of complications

\begin{tabular}{|c|c|c|c|c|c|}
\hline \multirow[b]{2}{*}{ Complication } & \multicolumn{5}{|c|}{$\begin{array}{l}\text { Patients wanting information about complication at this risk level } \\
(\%)\end{array}$} \\
\hline & 1 in 10 & 1 in 20 & 1 in 50 & 1 in 100 & Any risk \\
\hline Death & 2 & 2 & 2 & 6 & 38 \\
\hline Permanent stroke & 0 & 0 & 4 & 4 & 28 \\
\hline Permanent cognitive disability & 0 & 0 & 4 & 6 & 30 \\
\hline Reoperation & 0 & 0 & 2 & 6 & 26 \\
\hline Myocardial infarction & 0 & 0 & 2 & 6 & 26 \\
\hline Arrhythmia & 0 & 0 & 2 & 6 & 26 \\
\hline Kidney failure & 0 & 2 & 2 & 8 & 24 \\
\hline Pulmonary embolus & 0 & 0 & 2 & 6 & 22 \\
\hline Deep vein thrombosis & 0 & 0 & 2 & 8 & 26 \\
\hline Moderate pleural effusion & 0 & 0 & 2 & 6 & 28 \\
\hline Wound infection & 0 & 0 & 2 & 6 & 20 \\
\hline Failure of sternal union & 0 & 0 & 2 & 6 & 26 \\
\hline Transient stroke & 0 & 0 & 2 & 6 & 24 \\
\hline Transient cognitive disability & 0 & 0 & 2 & 8 & 26 \\
\hline
\end{tabular}

INFLUENCE OF RISK INFORMATION ON THE DECISION TO ACCEPT TREATMENT

Few patients' decision to accept surgery appeared to depend on risk information; $8 \%$ of patients said that they might have changed their decision, had they been advised of the risks of permanent stroke and myocardial infarction. However, 92\% were clear that their decision to accept treatment would not have altered.

\section{Discussion}

RISK INFORMATION REQUIRED BY PATIENTS

The results of this study suggest that the complications about which patients most wish to be informed are death and stroke, findings that mirror current practice at RBH. Only $72 \%$ of patients reported being informed of the risk of death, but this almost certainly indicates poor recall as a pilot study confirmed that all patients were so informed. Patients on average requested information on five complications, considerably more than is standard practice at $\mathrm{RBH}$. More patients wished for information about the more remote and less serious complications of surgery than received it; however, individual requirements varied considerably. This spectrum of information requirements shown by these results can most conveniently be represented by considering three groups of patients: those requiring little or no information, those requiring information about major risks, and those requiring full or near full disclosure of all risks. A substantial proportion of patients (42\%) did not want any information at all, and over a quarter (26\%) wanted information on 10 or more risks. Moreover, patients appeared either not to want risk information or to require it irrespective of the probability of occurrence. Few patients differentiated between varying levels of risk.

COMPLICATIONS EXPERIENCED BY PATIENTS No patient in this series suffered significant neurological injury, although $60 \%$ reported one or more complications. This relatively high rate is explained in part by a high incidence of reported wound problems, including self limiting inflammation, lying outside the categories of wound infection or significantly delayed healing. A relatively high rate of postoperative complications might also be expected in the cohort of patients selected for tertiary centre follow up at $\mathrm{RBH}$ as opposed to that discharged for follow up locally. 
LIMITATIONS OF THE STUDY

Patients in the postoperative period might reasonably be expected to express different preferences for risk information from those faced with the uncertainties of future surgery, despite the fact that the interviewees were asked to consider the information they would have wanted before surgery. Although risk information may be less important to patients successfully treated, it is noteworthy that the rates of complication reported in the study did not appear to influence the requirements for risk information. The study described is inevitably influenced by the characteristics of the patient population seen at $\mathrm{RBH}$ and potential bias may exist in relation to levels of educational attainment and socioeconomic group. Such bias would be expected to produce higher levels of demand for risk information; it is possible therefore that this study overestimated the proportion of patients seeking maximum disclosure of risk information. However, this would not be expected to invalidate the finding of widely differing information requirements within a single cohort of patients.

\section{IMPLICATIONS OF THE STUDY}

The findings indicate that a real benefit may be gained from identifying at an early stage three groups of patients: those who wish to be provided with information concerning even remote risks, those who only want information on major risks, and those who wish to receive little or no risk information. This should allow full disclosure of risk information when required without imposing unwanted risk information on patients who do not wish to receive it.

Any proposed classification of patients in this way might be expected to have both advantages and disadvantages for clinicians. ${ }^{16}$ On the one hand, differentiation should allow respectful tailoring of the style and content of individual consultations; on the other, clinicians would need to be watchful for errors in the process, remaining alert and ready to adapt to other expressions of patient preference. Problems might also arise where patients who would normally wish to be actively involved in decision making change their patterns of behaviour when faced with a procedure they hope to avoid. ${ }^{17}$

The findings of this study indicate that the "reasonable patient" test, which has slowly found its way into judicial decisions, may still fail to reflect patients' needs. The wide variation in individual information requirements undermines any concept of a reasonable patient. Furthermore, the finding that patients are generally insensitive to degrees of probability undermines the basis for adopting the Sidaway $v$ Bethlem \& Maudsley Hospitals guidelines.

This study suggests that guidelines for disclosure need to be more flexible, so as to cater for the needs of patients who wish to "know everything" without forcing more "traditional" types of patients to consider risks they would prefer to remain undisclosed. Patients may need to be encouraged to establish and communicate their preferences for disclosure of risk information. As a first step clinicians may, before discussing risks of any kind, ask patients for some indication as to the degree of information sought. They might be asked, for example, to choose among categories of "no risk information", "all potentially applicable risks," or "those risks considered significant or likely to occur". This information may be collected as part of the registration process and recorded in the notes, enabling subsequent written and verbal risk information to be adapted to patients' individual requirements.

\section{FURTHER RESEARCH}

Future studies, in addition to replicating the present findings, should also examine the reasons underlying individual patient preferences and the factors discriminating between patients who wish to be fully informed and those who wish to remain ignorant of risk. Any long term implications of these preferences might also be usefully explored, particularly in situations of adverse outcome. "Ignorance is bliss" may prove to be an excellent preoperative strategy for patients when outcome is good but detrimental to long term adjustment where significant postoperative complications arise.

\section{Appendix}

Summary of patient education initiatives

\begin{tabular}{|c|c|}
\hline Initiative & Comments \\
\hline Information pack & $\begin{array}{l}\text { Sent when patient placed on waiting list for surgery. Detailed information is given: } \bullet \text { Preparing for your heart operation-provides } \\
\text { information about the structure and function of the heart, different heart diseases, types of surgery, preparation for surgery, } \\
\text { postoperative pain management and recovery, postoperative education, discharge from hospital, and rehabilitation } \bullet \text { Inpatient } \\
\text { information - including patients' rights regarding consent to operation }\end{array}$ \\
\hline Presurgery preparation day & $\begin{array}{l}\text { Attendance is advised, although patients who are unable to attend receive information packs. The day lasts about } 4 \mathrm{~h} \text { with a break for } \\
\text { lunch and is run by the cardiac liaison nurse. Topics covered: } \bullet \text { management of waiting lists } \bullet \text { how the heart works } \bullet \text { types of heart } \\
\text { operation } \bullet \text { pre- and postoperative care } \bullet \text { discharge from hospital } \bullet \text { Two videos are shown: Intensive care-your recovery after surgery } \\
\text { and Life after heart surgery. }\end{array}$ \\
\hline Preadmission clinic & $\begin{array}{l}\text { The preadmission clinic is available for patients with a date for surgery. They can attend up to one month before their date of surgery. } \\
\text { Attendance is compulsory for suitable patients. The morning component of the clinic is educational and the afternoon is spent } \\
\text { completing tests and assessments. The clinic nurse gives patients an introductory talk on heart disease and an explanation of the } \\
\text { operative procedure. A current patient talks about what the experience really feels like. An intensive treatment unit nurse speaks on } \\
\text { immediate postoperative recovery, a physiotherapist speaks about postoperative mobility, and an occupational therapist speaks about } \\
\text { resuming activities after surgery. In the afternoon patients are clerked and their consent and operative treatment obtained and } \\
\text { documented. The clinic nurse might quote the average risk of operative complications but this information is rarely requested }\end{array}$ \\
\hline Postoperative education & $\begin{array}{l}\text { While the patient is in hospital she or he is encouraged to attend a series of ward teaching sessions held in the afternoons. They cover } \\
\text { physiotherapy, pharmacy, diet, nursing, and occupational therapy }\end{array}$ \\
\hline Cardiac rehabilitation & Patients are advised to attend a class six weeks after surgery covering all aspects of rehabilitation including exercise, stress reduction, etc \\
\hline
\end{tabular}


We would like to thank The BUPA Foundation and Royal Brompton and Harefield NHS Trust Clinical Research Brompton and Harefield NHS
Committee for funding this study.

1 Bogardus ST Jr, Holmboe E, Jekel JF. Perils, pitfalls and responsibilities in talking about medical risk. $\mathcal{F} A M A$ 1999;281:1037-41.

2 Pichert JW, Hickson GB. Communicating risk to patients and families. In: Vincent CA, editor. Clinical Risk Management, 2nd ed. London: BMJ Publishing Group, 2001:263ment,

3 Edwards MH. Satisfying patients' needs for surgical information. Br f Surg 1990;77:463-5.

4 Bridgewater B, Neve H, Moat N, et al. Predicting operative risk for coronary artery surgery in the United Kingdom: a comparison of various risk prediction algorithms. Heart 1998;79:350-5.

5 Ley P. Communicating with patients. Cheltenham: Stanley Thornes, 1988:27-52

6 Turner S, Maher EJ, Young T, et al. What are the information priorities for cancer patients involved in treatment decisions? An experienced surrogate study in Hodgkin's disease. Br F Cancer 1996;73:222-7.

7 Kessler S, Levine EK. Psychological aspects of genetic counselling IV. The subjective assessment of probability. Am 7 Med Genet 1987;28:363-70.
8 Hallowell N, Green JM, Statham H, et al. Recall of numerical risk estimates and counsellees' perceptions of the importance of risk information following genetic counselling for breast and ovarian cancer. Psychol Health Med 1997;2:149-59.

9 Beyth-Marom R. How probable is probable? A numerical translation of verbal probability expressions. $\mathcal{F}$ Forecasting 1982;1:257-69.

10 Sidaway v Bethlem \& Maudsley Hospitals [1985] AC 871.

11 Pearce v United Bristol Healthcare NHS Trust [1999] PIQR (CA)

12 White DR, Muss HB, Michielutte R, et al Informed consent: patient information forms in chemotherapy trials. $A m \mathcal{F}$ Clin Oncol 1984;7:183-90.

$13 \mathrm{Lim} \mathrm{HB}$, Soon KH, Ismar I, et al. Information on elective operations: let's hear what the patients have to say! Yorkshire Med 1999; Spring:44-5.

14 Feldman-Stewart D, Brundage MD, Hayter C, et al. What questions do patients with curable prostate cancer want answered? Med Decis Making 2000;20:7-19.

15 Seymour L, Woloshynowych M, Adams S. Patient perception of the risk associated with elective heart surgery. Healthc Risk Resour 2000;3:8-11.

16 Guadagnoli E, Ward P. Patient participation in decision making. Soc Sci Med 1998;47:329-39.

$17 \mathrm{Lidz}$ CW, Meisel A, Osterweiss M, et al. Barriers to informed consent. Ann Intern Med 1983;99:539-43.

\section{IMAGES IN CARDIOLOGY}

\section{Coil embolisation of isolated congenital coronary arteriovenous fistula causing myocardial ischaemia}

Congenital coronary arteriovenous fistula is a relatively rare anomaly that can cause severe symptoms, especially in older patients.

A 69 year old woman presented complaining of a recent onset of angina. She had a positive exercise test at intermediate workload (angina and ST segment depression $\geqslant 2 \mathrm{~mm}$ ). Coronary angiography revealed the absence of obstructive disease of the epicardial vessel, while an evident arteriovenous fistula originating from the mid portion of the left anterior descending coronary artery was documented. The drainage site of the isolated fistula was the trunk of the pulmonary artery. The malformation was successfully occluded by the percutaneous embolisation of four Guglielmi detachable platinum coils (Target Therapeutics, Fremont, California, USA).

The patient was discharged the day after the procedure and was completely asymptomatic three months later.

GIAN BATTISTA DANZI CINZIA CAPUANO

MARCO SESANA ALBERTO DI BLASI newpoli@tin.it
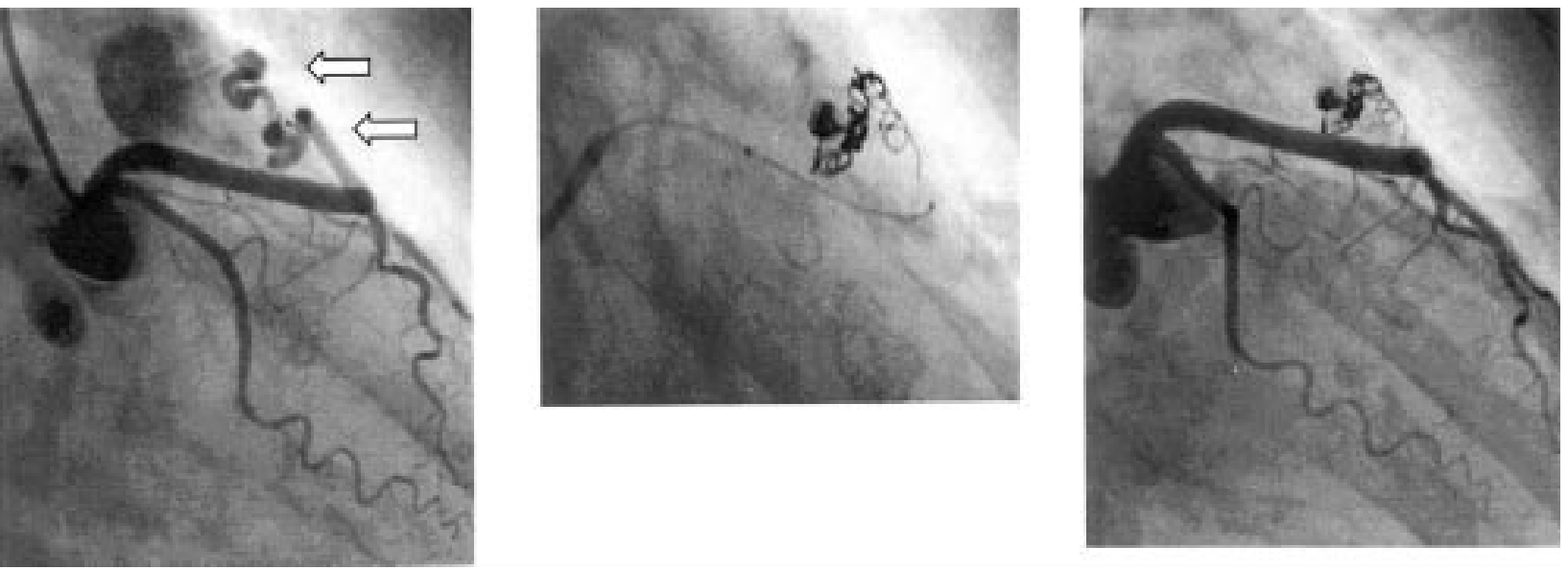

Left: congenital isolated coronary arteriovenous fistula originating from the mid portion of the left descending coronary artery and draining into the pulmonary artery trunk (arrows). Middle: percutaneous embolisation using four Guglielmi platinum coils. Right: final angiographic result with complete occlusion of the malformation. 